ảnh bất thường cân phải phân biệt
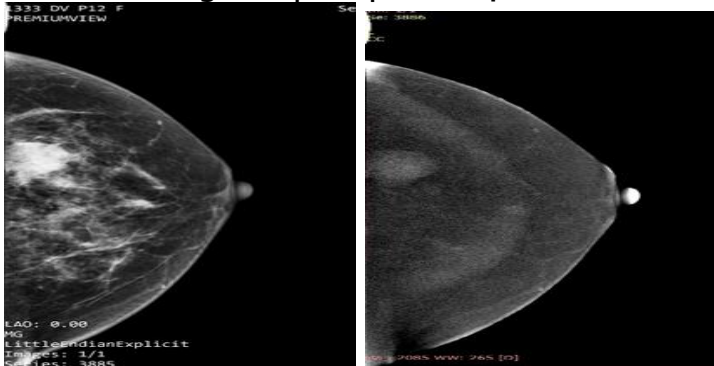

Hình ảnh minh họa khối u vú phải với tư thễ chụp từ trên xuống, trước và sau tiêm thuốc cản quang, xuất hiện nốt ngấm thuốc nhỏ hơn phía trước, ngay sau núm vú. Kết quả mô bệnh học là ung thư biểu mô ống xâm nhập.

\section{KẾT LUÂ̂N}

Hình ảnh Chụp XQ tuyến vú phổ hai mức năng lượng CESM đánh giá hiệu quả những tổn thương tăng đậm độ, thể hiện rõ ràng tính chất khối, ít bỏ sót tổn thương, do đó có giá trị trong việc chẩn đoán ung thư vú với các đối tượng có tuyến vú đậm đặc.

TÀl LIỆ THAM KHẢO
1. Nada A.M.A.M., Hamdi R., Shokry A. (2017). Dual energy contrast enhanced soft tissue digital mammography versus ultrasound elastography in the evaluation of breast masses. The Egyptian Journal of Radiology and Nuclear Medicine, 48(4), 1179-1186.

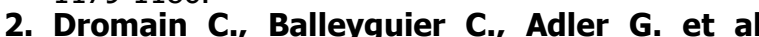
(2009). Contrast-enhanced digital mammography. Eur J Radiol, 69(1), 34-42.

3. Sung J.S., Lebron L., Keating D. et al (2019). Performance of Dual-Energy Contrast-enhanced Digital Mammography for Screening Women at Increased Risk of Breast Cancer. 293(1), 81-88.

4. Spak D.A., Plaxco J.S., Santiago L. et al (2017). BI-RADS((R)) fifth edition: A summary of changes. Diagn Interv Imaging, 98(3), 179-190.

5. Nguyến Văn Thắng (2013), Nghiên cứu giá trị chẩn đoán ung thư vú của chup $X$ quang kêt hợp siêu âm tuyến vú, Luận văn thạc sĩ y học, Đại học Y Hà Nội.

6. Costantini M., Belli P., Lombardi R. et al (2006). Characterization of solid breast masses: use of the sonographic breast imaging reporting and data system lexicon. J Ultrasound Med, 25(5), 649-659; quiz 661.

7. Berg W.A., Gutierrez L., NessAiver M.S. et al (2004). Diagnostic accuracy of mammography, clinical examination, US, and MR imaging in preoperative assessment of breast cancer. Radiology, 233(3), 830-849.

\title{
PHÂN TÍCH CHI PHÍ ĐIỀU TRI BÊNH PHỔI TẮC NGHẼN MAN TÍNH THEO QUAN ĐIỂM NGƯỜI CHI TRẢ TẠI BỆNH VIỆN QUẦN 11
}

\section{Dương Thái Bình ${ }^{1}$, Đặng Thị Ngọc² ${ }^{2}$ Nguyễn Thị Xuân Liễu ${ }^{3}$, Trương Thị Thu Hoàn ${ }^{2}$, Nguyễn Thị Thu Thuỷ ${ }^{1}$}

\section{TÓM TẮT}

Mở đâu: Bệnh phổi tắc nghẽn mạn tính (COPD Chronic Obstructive Pulmonary Disease) hiện nay đang trở thành một trong những vấn đề bệnh lý nghiêm trong gây ra bênh tât và tử vong hàng đầu trên thế giới cũng như tại Việt Nam. Trên thế giới đã có những nghiên cứu nhằm phân tích chi phí trong điều trị COPD và đây cũng là 1 trong những bước quan trọng nhằm cung cấp cái nhìn tổng quan về gánh năng kinh tế của bênh tại Việt Nam. Mục tiêu: Phân tích chi phí điều trì bểnh phổi tắc nghẽn man tính theo quan điểm ngườ chi trả tại bệnh viện Quận 11. Phương pháp nghiên cứu: Mổ tả cắt ngang dựa trên dữ liêu thu thập từ hồi cứu hồ sơ bệnh án và phỏng vấn toàn bộ người bệnh

${ }^{1}$ Đại học Y Dược Thành phố Hồ Chi Minh

²Bênh viện Quận 11, Thành phố Hồ Chí Minh

${ }^{3}$ Trường Đại học Nguyễn Tất Thành

Chiu trách nhiểm chính: Nguyễn Thị Thu Thuỷ

Email: nguyenthuthuy@ump.edu.vn

Ngày nhận bài: 14.6.2021

Ngày phản biện khoa học: 9.8.2021

Ngày duyệt bài: 18.8.2021 phổi tắc nghẽn mạn tính đến khám và điều trị tại Bệnh viện Quận 11 trong thời gian từ tháng 2 đến hết tháng 5 năm 2021 thỏa tiêu chí lựa chon và loai trừ. Nghiên cứu được thực hiên theo quan điểm người chi trả bao gồm cơ quan chi trả BHYT và người bệnh vì vậy các chi phí trực tiếp (y tế, ngoài y tế) và gián tiếp được đánh giá. Kết quả: Chi phí mỗi tháng điều trị tăng dần theo mức độ nặng của bênh với giá trị lần lướt là 78.478,22; 214.303,02; 267.937,06; 713.248,11 đồng cho các giai đoan từ GOLD A đến GOLD D. Như vây chi phí điều trị giai đoạn GOLD D gấp 9,09 lần giai đoạn GOLD A. Về cấu trúc, chi phí trực tiếp y tế chiếm tỷ lê cao nhất ở cả 4 giai đoan bênh, tiếp theo là chi phí gián tiếp và thấp nhất là chi phí trực tiếp ngoài y tế. Kết luân: Nghiên cứu ghi nhân tổng chi phí 1 tháng điều trị của người bệnh COPD tăng dần theo mức độ nặng của bệnh và chi phí trực tiếp y tế chiếm tỷ lề cao nhất.

Tư khoá: bênh phổi tắc nghẽn mạn tính, chi phí điều trị, bệnh viện quận 11

\section{SUMMARY \\ ANALYZE TREATMENT COST OF CHRONIC OBSTRUCTIVE PULMONARY DISEASE}




\section{FROM THE PAYERS' PERSPECTIVE IN DISTRICT 11 HOSPITAL}

Background: Chronic Obstructive Pulmonary Disease (COPD) is now becoming one of the medical problems leading to morbidity and mortality in the world as well as in Vietnam. Worldwide, researches on the treatment cost of COPD have been conducted in many countries and this is also one of the important to provide an overview of COPD treatment in Vietnam. Objectives: Analyzing the cost of treatment of chronic obstructive pulmonary disease from the payer perspective in district 11 hospital. Method: Crosssectional descriptive study based on data collected from retrospective medical records and interviews with COPD inpatients and outpatients, meeting the selection criteria of District 11 Hospital during the period from February to the end of May 2021. The research was conducted from the payers' perspective including the health insurance payer and the patient, so direct (medical, non-medical) and indirect costs were assessed. Results: The monthly treatment cost increased gradually according to the severity of the disease with the value of $78,478.22$; 214,303.02; $267,937.06$ and VND $713,248.11$ for stages from GOLD A to GOLD D; respectively. Thus, the cost of treatment for GOLD D stage is 9.09 times higher than that of GOLD A stage. In terms of structure, direct medical costs accounted for the highest proportion in all 4 disease stages, followed by indirect costs and non-medical direct costs was lowest. Conclusions: The study noted that the total monthly cost of treatment of COPD increased gradually with the severity of the disease and direct medical costs accounted for the highest proportion.

Keywords: chronic obstructive pulmonary disease, cost of treatment, district 11 hospital.

\section{I. ĐĂ̆T VẤN ĐỀ}

Bệnh phổi tắc nghẽn mạn tính (COPD Chronic Obstructive Pulmonary Disease) hiện nay đang trở thành một trong những vân đề bệnh lý nghiêm trọng gây ra bệnh tật và tử vong hàng đầu trên thế giới cũng như tại Việt Nam. COPD được ghi nhận là nguyên nhân gây tử vong thứ năm trên toàn thế giới, được dự đoán sẽ xếp thứ ba thế giới vào năm 2020 [1]. Tỷ lệ mắc và tử vong cao do COPD về cơ bản làm tăng gánh nặng tài chính cho ngân sách nhà nước [2]. Ở châu Âu, chi phí cho các bênh hô hấp ước tính bằng $6 \%$ ngân sách được phân bổ cho chăm sóc sức khỏe. Trong số này, 56\% được phân bổ cho việc điều trị bệnh nhân COPD, tạo ra chi phí khoảng 38,7 tỷ EURO hàng năm và gây mất 66.155 ngày làm việc trên tổng số 100.000 dân, chiếm $62,4 \%$ tổng số người nghỉ việc liên quan đến công việc. Tồng chi phí liên quan đến COPD ở Mỹ ước tính khoảng 36,1 tỷ USD, trong đó 20,9 tỷ là chi phí trực tiếp $[3,4]$. Ở Ba Lan, chi phí điêu trị đợt cấp COPD trung bình tại bệnh viện là gần 1.200 EURO, chi phí trực tiếp y tế chiếm 70\% [5]. Việc phân tích chi phí điều trị COPD là vấn đề cấp bách nhằm đánh giá tác động về mă̆t kinh tế của căn bênh này đối với người bệnh và cộng đồng. Tuy nhiên tại Việt Nam nghiên cứu tương tự vẫn chưa được thực hiện. Vì vậy nghiên cứu được thực hiện nhằm phân tích giá trị và cấu trúc chi phí điều trị bệnh COPD theo quan điểm người chi trả.

\section{II. ĐỐI TƯợNG VÀ PHƯƠNG PHÁP NGHIÊN CỨU}

Đối tượng nghiên cứu. Người bệnh COPD điều trị tại bệnh viện Quận 11.

Phương pháp nghiển cứu. Mô tả cắt ngang dựa trên dữ liệu hồi cứu hồ sơ bệnh án và phỏng vẩn trực tiếp người bệnh bằng phiếu phỏng vấn. Chi phí điều trị COPD được đánh giá bao gồm chi phí điều trị nội trú và ngoai trú của người bênh COPD cùng với số đợt nội trú và ngoại trú của người bệnh trung bình trong 1 tháng. Nghiên cứu thực hiên trên quan điểm người chi trả vì vây chi phí điều tri nội trú và ngoai trú bao gồm chi phí trực tiếp y tế (CP TTYT), chi phí trực tiếp ngoài y tế (CP TTNYT) và chi phí gián tiếp (CP GT). Trong đó chi phí trực tiếp y tế bao gồm các chi phí dich vu y tế và chi phí thuốc. Chi phí trực tiếp ngoài y tế gồm chi phí di chuyển, ăn uống và các chi phí khác; chi phí gián tiếp bao gồm thu nhập mất đi của người bệnh và người thân trong quá trình điều trị.

Mẫu nghiên cứu. Tất cả người bệnh COPD đến khám ngoại trú và/hoặc điêu trị nội trú tại Bênh viện Quận 11 từ tháng 2 đên hêt tháng 5 nẳm 2021 thoả mãn tiêu chí chọn mẫu.

\section{Tiêu chí lựa chon:}

- Người bệnh từ đủ 18 tuổi trở lên

- Người bệnh nghe, hiểu và viết được tiếng Việt

- Người bệnh đồng ý tham gia nghiên cứu

\section{Tiêu chí loại trư:}

- Người bệnh không cung cấp đầy đủ các thông tin cơ bản của phiếu khảo sát

- Người bệnh bỏ điều trị hoặc tự ý chuyển viện trong quá trình điêu trị

- Người bệnh có những bệnh mạn tính nặng kèm theo ảnh hưởng đến chi phí điều trị (ung thư, suy thận, viêm gan)

Thống kê và xử lý dữ liệu. Số liệu nghiên cứu được xử lý và thống kê bằng phần mềm thống kê SPSS 26 và Microsoft Excel 2016 với các phương pháp thống kê phù hợp. Số liệu được trình bày ở dạng hình và bảng.

\section{KẾT QUẢ NGHIÊN CứU}

Đặc điểm mẫu nghiên cứu. Mẫu nghiên cứu ngoại trú 
Khảo sát mẫu nghiên cứu gồm 122 người nghiên cứu ghi nhận đặc điểm mẫu nghiên cứu bệnh ngoại trú COPD tại bệnh viện Quận 11, trình bày trong bảng 1 .

Bảng 1. Đặc điểm mẫu nghiên cứu ngoại trú

\begin{tabular}{|c|c|c|c|c|c|}
\hline \multicolumn{2}{|c|}{ Đăc điếm } & Tân số (\%) & \multicolumn{2}{|c|}{ Đặc điếm } & Tân số (\%) \\
\hline \multirow{2}{*}{$\begin{array}{l}\text { Giới } \\
\text { tính }\end{array}$} & Nũ̃ & $8(6,6)$ & \multirow{4}{*}{$\begin{array}{l}\text { Nhóm } \\
\text { bệnh }\end{array}$} & GOLD A & $16(13,1)$ \\
\hline & Nam & $114(93,4)$ & & GOLD B & $26(21,3)$ \\
\hline \multirow{3}{*}{ BHYT } & $80 \%$ & $95(77,9)$ & & GOLD C & $22(18,0)$ \\
\hline & $95 \%$ & $5(4,1)$ & & GOLD D & $58(47,5)$ \\
\hline & $100 \%$ & $22(18,0)$ & \multirow{4}{*}{$\begin{array}{l}\text { Chỉ số } \\
\text { FEV1 }\end{array}$} & $\geq 80 \%$ & $5(4,1)$ \\
\hline \multirow{5}{*}{$\begin{array}{l}\text { Nghề } \\
\text { nghiệp }\end{array}$} & Buôn bán/Tự kinh doanh & $4(3,3)$ & & $50-79 \%$ & $23(18,9)$ \\
\hline & $\begin{array}{l}\text { Công nhân/Lao động } \\
\text { chân tay }\end{array}$ & $20(16,4)$ & & $30-49 \%$ & $48(39,3)$ \\
\hline & Đã nghỉ hưu & $78(63,9)$ & & $<30 \%$ & $46(37,7)$ \\
\hline & Thất nghiệp/Không việc làm & $18(14,8)$ & Tăng & Có & $34(27,9)$ \\
\hline & Khác & $2(1,6)$ & huyết áp & Không & $88(72,1)$ \\
\hline \multirow{6}{*}{$\begin{array}{c}\text { Trình } \\
\text { độ } \\
\text { học } \\
\text { vẩn }\end{array}$} & Không đi học & $15(12,3)$ & Tiểu & Có & $2(1,6)$ \\
\hline & Tiểu học & $60(49,2)$ & & Không & $120(98,4)$ \\
\hline & Tốt nghiệp THCS & $32(26,2)$ & \multirow{4}{*}{$\begin{array}{l}\text { Số bệnh } \\
\text { kèm }\end{array}$} & 0 bệnh kèm & $29(23,8)$ \\
\hline & Tốt nghiệp THPT & $10(8,2)$ & & 1 bệnh kèm & $27(22,1)$ \\
\hline & Đại học & $4(3,3)$ & & 2 bệnh kèm & $27(22,1)$ \\
\hline & Sau đại học & $1(0,8)$ & & 3 bệnh kèm & $26(21,3)$ \\
\hline \multirow{2}{*}{\multicolumn{2}{|c|}{$\begin{array}{c}\text { Đặc điếm } \\
\text { Tuối } \\
\end{array}$}} & \multicolumn{2}{|c|}{ GTTB \pm ĐLC } & \multicolumn{2}{|c|}{ GTNN-GTLN } \\
\hline & & \multirow{2}{*}{\multicolumn{2}{|c|}{$\begin{array}{c}67,54 \pm 9,14 \\
278581967 \pm 280993451\end{array}$}} & \multicolumn{2}{|c|}{$50-99$} \\
\hline \multirow{2}{*}{\multicolumn{2}{|c|}{$\begin{array}{c}\text { Thu nhập trung bình tháng (VND) } \\
\text { Số đơt nhâp viên } 12 \text { tháng }\end{array}$}} & \multirow{2}{*}{\multicolumn{2}{|c|}{$\frac{2.785 .819,67 \pm 2.809 .934,51}{0,35 \pm 0,99}$}} & \multirow{2}{*}{\multicolumn{2}{|c|}{$0-13.000 .000$}} \\
\hline Số c & & & & & \\
\hline
\end{tabular}

Ghi chú: GTTB: giá trị trung bình; ĐLC: độ lệch chuấn; GTLN: giá trị lớn nhất; GTNN: giá trị nhỏ nhất.

Theo bảng 1, nghiên cứu ghi nhận mẫu ngoại trú có tỷ lệ nam nữ là 14,25:1 với tuổi thọ trung bình 67,54 \pm 9,14 tuổi và dao động từ 50-99 tuổi. Về mức hưởng bảo hiểm y tế, $77,90 \%$ mẫu nghiên cứu có mức hưởng $80 \%$ và chiếm đa số. Phần lớn người bệnh có trình độ tiểu học với tỷ lệ 49,20\%; tiếp theo là trình độ THCS (26,20\%) và có đến $12,30 \%$ không đi học. Về nghề nghiệp, người bệnh đã nghỉ hưu chiếm đa số với tỳ lệ $63,90 \%$; tiếp theo là nhóm người bệnh công nhân/lao động chân tay và thất nghiệp với tỷ lệ lần lượt là $16,40 \%$ và $14,80 \%$. Phần lớn người bệnh trong mẫu ngoại trú thuộc nhóm bệnh GOLD D (47,50\%), tiếp theo là người bệnh thuộc nhóm $G O L D B$ và $C$ với tỷ lệ lần lượt là $21,30 \%$ và $18,00 \%$; người bệnh nhóm GOLD $A$ có tỷ lệ thấp nhất (13,10\%). Đa số người bệnh có chỉ số $\mathrm{FEV}_{1}$ từ 30 - 49\% với $39,30 \%$; có $4,10 \%$ có có chỉ số $\mathrm{FEV}_{1} \geq 80 \%$ và chiếm tỷ lệ thấp nhất. Về bệnh kèm theo, 27,90\% mắc tăng huyết áp và $1,60 \%$ mắc bệnh tiểu đường; 23,80\% không có bệnh kèm. Số đợt nhập viện trung bình trong 12 tháng của người bệnh có giá trị $0,35 \pm 0,99$ và dao động từ $0-6$ đợt. Thu nhập trung bình của mẫu nghiên cứu có giá trị 2.785.819,67 $\pm 2.809 .934,51$ đồng và dao động từ 0 đến 13 triệu đồng.

Mẫu nghiển cứu nội trú. Khảo sát mẫu nghiên cứu gồm 30 người bệnh COPD điều trị nội trú tại bệnh viện Quận 11 , nghiên cứu ghi nhận đặc điểm mẫu nghiên cứu trình bày trong bảng 2 .

Bảng 2. Đặc điểm mẫu nghiên cứu nội trú

\begin{tabular}{|c|c|c|c|c|c|}
\hline \multicolumn{2}{|c|}{ Đặc điếm } & Tần số (\%) & \multicolumn{2}{|c|}{ Đặc điếm } & Tần số (\%) \\
\hline \multirow{2}{*}{$\begin{array}{l}\text { Giới } \\
\text { tính }\end{array}$} & Nữ & $3(10,0)$ & \multirow{4}{*}{$\begin{array}{l}\text { Giai đoạn } \\
\text { bệnh }\end{array}$} & GOLD A & $3(10,0)$ \\
\hline & Nam & $27(90,0)$ & & GOLD B & $7(23,3)$ \\
\hline \multirow{3}{*}{ BHYT } & $80 \%$ & $23(76,7)$ & & GOLD C & $7(23,3)$ \\
\hline & $95 \%$ & $3(10,0)$ & & GOLD D & $13(43,3)$ \\
\hline & $100 \%$ & $4(13,3)$ & \multirow{3}{*}{$\begin{array}{l}\text { Chỉ số } \\
\text { FEV1 }\end{array}$} & & \\
\hline \multirow{2}{*}{$\begin{array}{l}\text { Nghề } \\
\text { nghiệp }\end{array}$} & Buôn bán/Tự kinh & $2(6,7)$ & & $50-79 \%$ & $2(6,7)$ \\
\hline & Công nhân/Lao & $1(3,3)$ & & $30-49 \%$ & $12(40,0)$ \\
\hline
\end{tabular}




\begin{tabular}{|c|c|c|c|c|c|}
\hline & động chân tay & & & & \\
\hline & Đã nghỉ hưu & $22(73,3)$ & & $<30 \%$ & $16(53,3)$ \\
\hline & $\begin{array}{c}\text { Thất nghiệp /Không } \\
\text { viêc làm }\end{array}$ & $4(13,4)$ & \multirow{2}{*}{$\begin{array}{l}\text { Tăng } \\
\text { huyết áp }\end{array}$} & Có & $8(26,7)$ \\
\hline & Khác & $1(3,3)$ & & Không & $22(73,3)$ \\
\hline \multirow{7}{*}{$\begin{array}{l}\text { Trình } \\
\text { độ } \\
\text { hộc } \\
\text { vẩn }\end{array}$} & Không đi học & $2(6,7)$ & \multirow{2}{*}{$\begin{array}{l}\text { Tiểu } \\
\text { đường }\end{array}$} & Có & $1(3,3)$ \\
\hline & Tiếu học & $16(53,3)$ & & Không & $29(96,7)$ \\
\hline & Tốt nghiệp THCS & $7(23,3)$ & \multirow{5}{*}{$\begin{array}{l}\text { Số bệnh } \\
\text { kèm }\end{array}$} & 0 bệnh kèm & $6(20,0)$ \\
\hline & Tốt nghiệp THPT & $2(6,7)$ & & 1 bệnh kèm & $8(26,7)$ \\
\hline & Đại học & $2(6,7)$ & & 2 bệnh kèm & $7(23,3)$ \\
\hline & \multirow{2}{*}{ Sau đại học } & \multirow{2}{*}{$1(3,3)$} & & 3 bệnh kèm & $6(20,0)$ \\
\hline & & & & $>4$ bệnh kèm & $3(10,0)$ \\
\hline \multicolumn{2}{|r|}{ Đặc điếm } & \multicolumn{2}{|c|}{ GTTB \pm ĐLC } & \multicolumn{2}{|c|}{ GTNN-GTLN } \\
\hline & Tuối & \multicolumn{2}{|c|}{$66,40 \pm 9,58$} & \multicolumn{2}{|c|}{$51-90$} \\
\hline \multicolumn{2}{|c|}{$\begin{array}{c}\text { Thu nhập trung bình tháng } \\
\text { (VNĐ) }\end{array}$} & \multicolumn{2}{|c|}{$3.227 .666,67 \pm 2.143 .490,04$} & \multicolumn{2}{|c|}{$150.000-8.000 .000$} \\
\hline \multirow{2}{*}{\multicolumn{2}{|c|}{$\begin{array}{l}\text { Thời gian nằm viện (ngày) } \\
\text { Số đợt nhâp viên } 12 \text { tháng }\end{array}$}} & \multirow{2}{*}{\multicolumn{2}{|c|}{$\frac{10,60 \pm 8,33}{1,22 \pm 0,61}$}} & \multicolumn{2}{|c|}{ 4-45 } \\
\hline & & & & \multicolumn{2}{|c|}{$0-2$} \\
\hline
\end{tabular}

Ghi chú: GTTB: giá trị trung bình; ĐLC: độ lệch chuấn; GTLN: giá trị lớn nhất; GTNN: giá trị nhỏ nhất

Theo bảng 2, nghiên cứu ghi nhận mẫu nội trú có tỷ lệ nam nữ là 9:1 với tuổi thọ trung bình $66,40 \pm 9,58$ tuổi và dao động từ 51-90 tuổi. Về mức hưởng bảo hiểm y tế $76,70 \%$ người bệnh có mức hưởng $80 \%$ và chiếm đa số. Hơn phân nửa người bệnh có trình độ tiểu học với tỷ lệ $53,30 \%$; tiếp theo là trình độ $\mathrm{THCS}(23,30 \%)$ và trình độ sau đại học chiếm tỷ lệ thấp nhất là 3,30\%. Về nghề nghiệp, người bệnh đã nghỉ hưu chiếm đa số với tỷ lệ $73,30 \%$; tiếp theo là nhóm người bệnh buôn bán/tự kinh doanh, nội trợ và thất nghiệp/không có việc làm với tỷ lệ bằng nhau $(6,70 \%)$. Phần lớn người bệnh trong mẫu ngoại trú thuộc nhóm bệnh GOLD D với 43,30\%, tiếp theo là nhóm GOLD $B$ và $C$ chiếm tỷ lệ bằng nhau $(23,30 \%)$; thấp nhất là nhóm GOLD $A$ với $10,00 \%$. Người bệnh có chỉ số $\mathrm{FEV}_{1}<30 \%$ chiếm đa số với $53,30 \%$. Về bệnh kèm theo, có
$26,70 \%$ mắc tăng huyết áp và 3,30\% mắc bệnh tiểu đường và có $20,00 \%$ không có bệnh kèm. Thu nhập trung bình 3.227.666,67 \pm $2.143 .490,04$ đồng và dao động từ 150.000 đến 8.000 .000 .000 đồng. Thời gian nằm viện trung bình $10,60 \pm 8,33$ ngày và dao động từ 4-45 ngày điều trị. Số đợt nhập viện trung bình trong 12 tháng của người bệnh có giá trị 1,22 $\pm 0,61$ và dao động từ $0-2$ đợt.

Chi phí điêuu trị bệnh phổi tắc nghẽn mạn tính trong 1 tháng

Khảo sát chi phí điều trị COPD trên mẫu nghiên cứu gồm 122 người bệnh ngoại trú và 30 người bệnh nội trú COPD điều trị tại Bệnh viện Quận 11 từ tháng 2 đến tháng $5 / 2021$ và tần suất khám nội trú/ngoại trú tại bệnh viện giai đoạn từ tháng 1 đến hết tháng 12/2020, đề tài ghi nhận kết quả trình bày trong bảng 3 .

Bảng 3. Tống chi phí điều trị COPD mỗi tháng theo từng giai đoạn bệnh

\begin{tabular}{|c|c|c|c|c|c|c|}
\hline $\begin{array}{c}\text { Giai } \\
\text { đoạn }\end{array}$ & $\begin{array}{l}\text { Thành } \\
\text { phân chi } \\
\text { phí }\end{array}$ & $\begin{array}{l}\text { Chi phí } 1 \\
\text { đợt ngoại } \\
\text { trú }\end{array}$ & $\begin{array}{c}\text { Số đợt } \\
\text { ngoại } \\
\text { trú /tháng }\end{array}$ & $\begin{array}{l}\text { Chi phí } 1 \\
\text { đợt nội trú }\end{array}$ & $\begin{array}{c}\text { Số đợt } \\
\text { nôii } \\
\text { trú /tháng }\end{array}$ & $\begin{array}{l}\text { Chi phí điêu } \\
\text { trị } 1 \text { tháng }\end{array}$ \\
\hline \multirow{4}{*}{$\begin{array}{c}\text { GOLD } \\
\text { A }\end{array}$} & CPTTYT & $515.436,56$ & \multirow{4}{*}{0,081} & $2.998 .033,99$ & \multirow{4}{*}{0,011} & $74.728,74$ \\
\hline & CPTTNYT & $23.453,35$ & & 0,00 & & $1.899,72$ \\
\hline & CPGT & $22.836,54$ & & 0,00 & & $1.849,76$ \\
\hline & TÖNG & $561.726,45$ & & $2.998 .033,99$ & & $78.478,22$ \\
\hline \multirow{4}{*}{$\begin{array}{c}\text { GOLD } \\
\text { B }\end{array}$} & CPTTYT & $477.760,37$ & \multirow{4}{*}{0,126} & $4.593 .607,07$ & \multirow{4}{*}{0,022} & $161.257,16$ \\
\hline & CPTTNYT & $29.678,30$ & & $504.685,19$ & & $14.842,54$ \\
\hline & CPGT & $51.849,11$ & & $1.439 .560,44$ & & $38.203,32$ \\
\hline & TÓNNG & $559.287,78$ & & $6.537 .852,70$ & & $214.303,02$ \\
\hline \multirow{4}{*}{$\underset{\text { C }}{\text { GOLD }}$} & CPTTYT & $573.799,89$ & \multirow{4}{*}{0,109} & $5.544 .390,01$ & \multirow{4}{*}{0,025} & $201.153,94$ \\
\hline & CPTTNYT & $29.460,82$ & & $664.613,84$ & & $19.826,58$ \\
\hline & CPGT & $48.951,05$ & & $1.664 .835,17$ & & $46.956,54$ \\
\hline & TÓNG & $652.211,76$ & & $7.873 .839,02$ & & $267.937,06$ \\
\hline
\end{tabular}




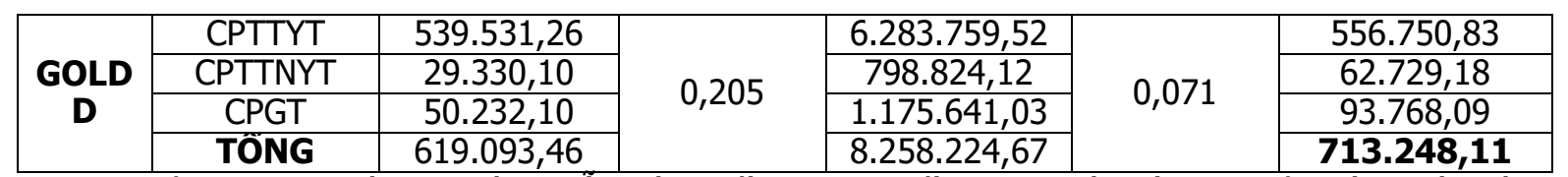

Theo bảng 3, chi phí trung bình mối tháng điều trị tăng dần theo mức độ nặng của bệnh với giá trị lần lượt là 78.478,22; 214.303,02; 267.937,06; 713.248,11 đồng cho các giai đoạn bệnh từ GOLD A đến GOLD D. Chi phí điều trị cho người bệnh ở giai đoạn GOLD D gấp 9,09 lần giai đoạn GOLD A. Điều này được giải thích bởi GOLD $D$ là giai đoạn nặng nhất, người bệnh cần phải sử dụng nhiều thuốc phối hợp cũng như tần suất nhập viện cao hơon so với các giai đoạn còn lại.

Phân tích cấu trúc chi phí trung bình mỗi tháng điều trị COPD, đề tài ghi nhận kết quả được trình bày trong hình 1.

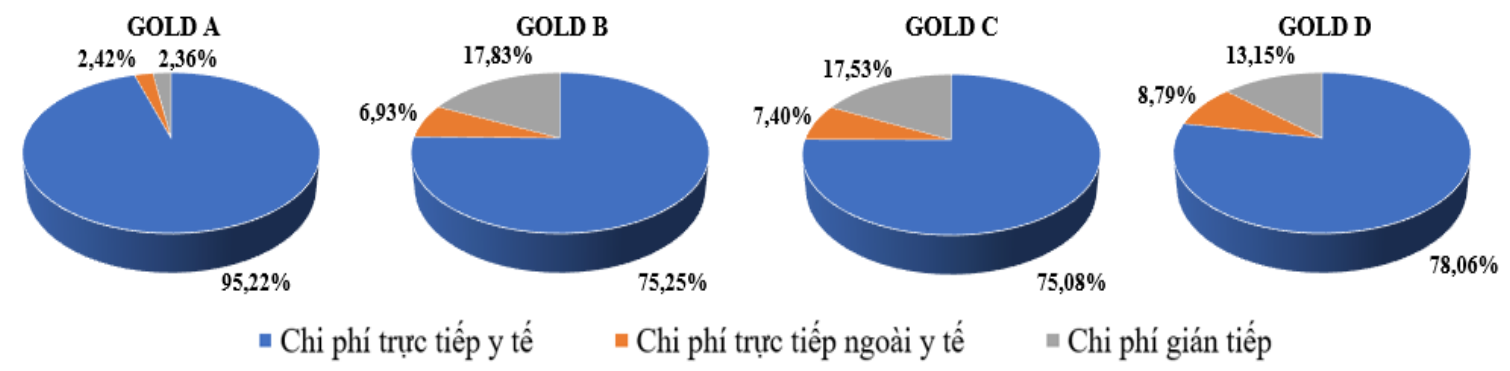

Hình 1. Cấu trúc chi phí điều trị bệnh phổi tắc nghẽn mạn tính theo giai đoạn bệnh

Theo hình 1, đề tài ghi nhận cấu trúc chi phí trung bình mỗi tháng điều trị bệnh phổi tắc nghẽn mạn tính tương đương ở cả 4 giai đoạn bệnh từ GOLD A đến GOLD D. Cụ thể, CPTTYT chiếm tỷ lệ cao nhất ở cả 4 giai đoạn bệnh và cao nhất ở GOLD A với 95,22\%, GOLD B - 75,25\%, GOLD C $75,08 \%$ và GOLD D - 78,06\%. Tiếp theo là CPGT với tỷ lệ dao động từ 2,36\% đến $17,83 \%$ và thấp nhất là CPTTNYT với tỷ lệ dao động từ 2,42\% đến 8,79\% ở 4 giai đoạn bệnh.

\section{BÀN LUÂNN}

Nghiên cứu được thực hiện tại Bệnh viện Quận 11. Tỷ lệ người bệnh ngoại trú và nội trú là 4:1. Trong đó, mẫu ngoại trú có tỷ lệ nam:nữ là $14,25: 1$ thấp hơn so với nghiên cứu dịch tễ của Namhee Kwon và cộng sự [6]. Tỷ lệ người bệnh đã nghỉ hưu chiếm đa số với độ tuổi trung bình là 67,54 tuổi cao hơn so với nghiên cứu của tác giả Nguyễn Thanh Hà và cộng sự [7] thực hiện tại bệnh viện Phổi Trung ương Hà Nội năm 2017. Với mẫu nội trú, tỷ lệ nam:nữ là $9: 1$, tương đương với nghiên cứu của Ngô Quý Châu và cô̂ng sự [8] về số người bệnh nội trú COPD tại Hà Nội năm 2018, tuy nhiên, độ tuổi trung bình của mẫu nội trú trong nghiên cứu thấp hỡn nghiên cứu này. Thu nhập trung bình ở cả 2 mẫu ngoại trú và nội trú trong nghiên cứu đều thấp hơn so với thu nhập bình quân đầu người mối tháng được công bố bởi Tổng Cục Thống kê quý IV năm 2020 (4.190.000 VNĐ) [9].

Nghiên cứu cho thấy chi phí điều trị trung bình mối tháng tăng theo mức độ nặng của bênh và cao nhất ở nhóm GOLD $D$, do đó việc kiểm soát diễn tiến của bệnh là rất quan trọng nhằm giúp giảm gánh nặng kinh tế của bệnh. Bên cạnh đó, trong cấu trúc chi phí, nghiên cứu cho thây chi phí trực tiếp y tế chiếm tỷ lệ cao nhất và trên $75 \%$ ở cả 4 giai đoạn bệnh, tỷ lệ này cao hơn so với nghiên cứu của Hilleman và cộng sự tại $\mathrm{Ba}$ Lan năm 2000 [5]. Vì vậy, giảm thiểu chi phí trực tiếp y tế bằng nhiều biện pháp có thể giúp giảm đáng kể gánh nặng kinh tế của bệnh.

\section{KẾT LUÂ̂N}

Khảo sát người bệnh điều trị COPD tại Bệnh viện Quận 11, nghiên cứu ghi nhận tổng chi phí điều trị trung bình mỗi tháng của người bệnh tăng dần theo mức độ nặng của bệnh với chi phí điều trị nhóm GOLD D là lớn nhất và chi phí trực tiếp y tế chiếm ưu thế. Vì vậy, nâng cao ý thức của người bệnh trong phát hiện sớm và tuân thủ điều trị giúp giảm tỷ lệ tiến triển bệnh nặng hơn có thể làm giảm đáng kể chi phí trực tiếp y tế đồng thời giảm gánh nặng kinh tế của bệnh.

\section{TÀI LIÊU THAM KHẢO}

1. World Health Organization (2015), "Chronic respiratory diseases, burden of chronic obstructive pulmonary disease", http://wwwwhoint/ respiratory/copd/burden/en/. Ngày truy cập: 20/10/2020.

2. Pauwels R. et al. (2004), "COPD exacerbations: 
the importance of a standard definition", Respiratory medicine. 98 (2), pp. 99-107.

3. GOLD (2011) From the global strategy for the diagnosis, management and prevention of COPD. Global Initiative for Chronic Obstructive Lung Disease. Available from: http://www.goldcopd.org. Ngày truy cập: 20/05/2021.

4. Mannino D. M. (2003), "Chronic obstructive pulmonary disease: definition and epidemiology", Respiratory care. 48 (12), pp. 1185-1193.

5. Hilleman D. E. et al. (2000), "Pharmacoeconomic evaluation of COPD", Chest. 118 (5), pp. 1278-1285.

6. Kwon N. et al. (2013), "Validity of the COPD assessment test translated into local languages for Asian patients", Chest. 143 (3), pp. 703-710.

7. Nguyen H. T. et al. (2019), "Nutritional status, dietary intake, and health-related quality of life in outpatients with COPD", International journal of chronic obstructive pulmonary disease. 14, pp. 215.

8. Ngo C. Q. et al. (2019), "Inhaler technique and adherence to inhaled medications among patients with acute exacerbation of chronic obstructive pulmonary disease in Vietnam", International journal of environmental research and public health. 16 (2), pp. 185.

9. Tổng quan kinh tế - xã hội Việt Nam năm 2020 , Tổng cục Thống kê.

\section{ĐÁNH GIÁ HIÊU QUẢ CỦA NEP Cổ TAY TRONG ĐÎ̀UU TRI HỐ TRỢ HộI CHỨNG ỐNG CỔ TAY}

\section{TÓM TẮT}

Hội chứng ống cổ tay là bệnh lý thần kinh ngoại biên phổ biến, có nhiều phưởng pháp điều trị khác nhau trong đó đeo nep cổ tay là một phương pháp hỗ trợ hữu hiệu trong điều trị hội chứng ống cố tay. Mục tiều: Đánh giá hiệu quả của nẹp cổ tay trong điều trị hố trợ hội chứng ổng cổ tay và xác định một số yếu tổ liên quan đến kết quả điêu trị. Đối tượng và phương pháp nghiên cứu: Nghiền cứu thử nghiệm lâm sàng có đối chứng theo dõi trong 2 tháng trên 63 bênh nhân hôi chứng ống cổ tay chia làm 2 nhóm: 32 bểnh nhân được dùng 1 loai thuốc NSAIDs trong 2 tuân kết hợp với đeo nẹp cổ tay trong 2 tháng, 31 bệnh nhân được dùng với duy nhất 1 loại thuốc NSAIDs trong 2 tuần. Kết quả: Sau 2 tháng điêuu trị, có sự cải thiện điểm VAS, điểm Boston triệu chứng và chức năng, tốc độ dẫn truyền thần kinh giữa và diện tích thần kinh giữa ở nhóm dùng NSAIDs và nẹp cổ tay: VAS trung bình giảm từ 2,0 xuống 0,4 điểm, Boston triệu chứng giảm từ 16,7 xuống 12,7 điểm, Boston chức năng giảm từ 11,4 xuống 8,7 điểm, tốc đô dẫn truyền cảm giác thần kinh giữa có cải thiện tăng từ 41,7 lên 45,8 (m/s), diện tích ngang thần kinh giữa có giảm từ 11.7 xuống $9.8\left(\mathrm{~mm}^{2}\right)$, cao hơn nhóm chứng $(p<0,05)$. Một số yếu tố liên quan đến kết quả điều tri: Tuối và BMİ có tương quan nghịch với sự thay đổi điểm VAS; thay đổi điểm Boston triệu chứng và chức năng. Kết luận: Nẹp cổ tay là phương pháp điều trị hỗ trợ có hiệu quả trong điêu trị hội chứng ống cổ tay.

Tư khóa: Nẹp cổ tay, Hội chứng ống cổ tay.

\footnotetext{
${ }^{1}$ Dại học Y Hà Nội

${ }^{2}$ Bềnh viện Bạch Mai

Chịu trách nhiệm chính: Trần Thị Tô Châu

Email: tranthitochau72@yahoo.com.au

Ngày nhận bài: 21.6.2021

Ngày phản biên khoa họ: 16.8.2021

Ngày duyệt bài: 23.8.2021
}

\section{Hà Thị Kim Khuyên ${ }^{1}$, Trần Thị Tô Châu ${ }^{2}$ \\ SUMMARY \\ EVALUATING THE EFFICACY OF SUPPORTIVE THERAPY OF SHORT WRIST SPLINT IN PATIENTS WITH CARPAL TUNNEL SYNDROME}

Carpal tunnel syndrome is the most common peripheral nerve entrapment syndrome worldwide 1 . There are availability of several therapies ranges from non-surgical to surgical management1. Short wrist splints is one of the most typically employed therapeutic procedures. Objectives: To evaluate the efficacies of supportive therapy of short wrist splint in patients with carpal tunnel syndrome under NSAIDs treatment and determind the factors interfering the treatment results. Methods: Controlled clinical trial were followed up to 2 months in 63 patients with carpal tunnel syndrome, divided into two groups: 32 patients received NSAIDs for 2 weeks and a standard wrist splint in neutral position to be worn at night, if possible, during the day, 31 patients were treated solely with NSAIDs for 2 weeks. Results: After 2 months of treatment, there were an improvement in VAS, Boston scores, Distal median motor latencies (DMLm) and median sensory conduction velocities (SCVm) in the research group: The average VAS were decreased from 2.0 to 0.4 points, Boston symptom scores were declined from 16.7 to 12.7 points, Boston functional scores were declined from 11.4 to 8.7 points, median sensory conduction velocities $(\mathrm{SCVm})$ were improved considerable from 41.7 to $45.8 \mathrm{~m} / \mathrm{s}$, the cross-sectional area of the median nerve (CSA) were fell from 11.7 to $9.8 \mathrm{~mm}^{2}$, higher than the placebo group $(p<0,05)$. The factors interfering the treatment results: Age and BMI negatively correlated with the change in VAS scores, Boston symptoms and function scores. Conclusion: A short wrist splint is effective therapy support in patients with carpal tunnel syndrome.

Key words: wrist splint, carpal tunnel syndrome.

I. ĐĂTT VẤN ĐỀ

Hội chứng ống cổ tay (HCOCT) là bệnh lý 